\title{
Listening Behaviour of Audience Farmers of Shahdol District of Madhya Pradesh towards Kisanvani Programme of All India Radio
}

\author{
Sumit Kumar Palvi", Seema Naberia and N.K. Khare \\ Department of Extension Education, College of Agriculture, Jawaharlal Nehru Krishi Vishwa \\ Vidyalaya, Jabalpur, Madhya Pradesh, India \\ *Corresponding author
}

\section{A B S T R A C T}

\begin{tabular}{|c|}
\hline Keywords \\
\hline $\begin{array}{l}\text { Audience farmers, } \\
\text { Kisanvani, } \\
\text { Listening } \\
\text { behaviour, Mass } \\
\text { media, Radio }\end{array}$ \\
\hline Article Info \\
\hline $\begin{array}{l}\text { Accepted: } \\
\text { 26 June } 2018 \\
\text { Available Online: } \\
\text { 10 July } 2018\end{array}$ \\
\hline
\end{tabular}

\section{Introduction}

A number of research institutions and agricultural universities have been established to generate the scientific know-how. In order to transfer the research results required to the farming community, a proper support and continued efforts are required to communicate these results through various media such as radio, television, print media and interpersonal communication channels. Among all mass communication media directed towards the farm population, radio perhaps is the most competent and has tremendous capacity to communicate the ideas with immediacy and continuous flow. Radio is considered as a credible source of information and is taken as authentic, trustworthy and prestigious medium of communication.

All India Radio has expanded the scope of agriculture broadcasts with the launch of an exclusive project on Mass Media support to Agriculture Extension entitled 'Kisanvani' from 15th February 2004. This is in collaboration with the Department of Agriculture and Cooperation, Ministry of Agriculture. The purpose is to keep local farmers informed about the agricultural information, practices, daily market rates, 
weather reports and day to day information in their respective areas at the micro level. Ninety six FM stations of All India Radio are broadcasting thirty minutes programme six days a week from 6.30-7.00 PM. Each of the currently covered 96 FM stations are broadcasting separate programme in respective dialects / languages. Kisanvani programme of All India Radio is being broadcast in only eight districts of Madhya Pradesh namely Balaghat, Betul, Chhindwara, Guna, Khandwa, Sagar, Shahdol and Shivpuri.

The listeners of Kisanvani programme are heterogeneous in respect to their personal, socio-economical, communicational and psychological characteristics. The effectiveness of Kisanvani programme needs to be ascertained for exploiting technology transfer. Theoretical exploration of Kisanvani programme / messages broadcasted in Kisanvani programme culminates into several questions / issues such as: What is the listening behaviour of the audience farmers of Kisanvani programme? Do the farmers listened complete/incomplete duration of Kisanvani programme? Do the farmers discussed the agricultural information broadcasted in Kisanvani programme and with whom? These questions need empirical answers in the context of present area and Kisanvani programme for effective transfer of farm technology to the farmers.

\section{Materials and Methods}

The present study was carried out during 2017-18 in the Shahdol district of Madhya Pradesh. Out of five blocks in the district, 2 blocks were selected purposively for the study due to the vicinity of the AIR Shahdol station the network coverage and strength are good in the villages of these selected blocks. From each block three villages were selected randomly, hence total 6 villages were selected for the study. From each village, 20 farmers were selected randomly thus 120 respondents were considered for the study. The data collection was done by the use of interview schedule through personal interview. Data were analyzed with help of suitable statistical tools.

Listening behaviour was operationalised as the regularity of listening, duration of listening, and discussion after listening the Kisanvani programme.

Regularity was operationalised as the frequency of listening different agricultural information broadcasted in Kisanvani programme and with the help of structural schedule it was measured on three-point continuum as always, sometimes and never and the scores 2, 1 and 0 were given respectively.

Duration was operationalised as the period of listening i.e., time spent by the respondent in listening the Kisanvani programme.

Discussion was operationalised as with whom the farmer discusses agricultural information after listeningKisanvani programmeand with help of structural schedule it was measured on three-point continuum as always, sometimes and never and the scores 2, 1 and 0 were given respectively.

The scores obtained by the respondents for all the three parameters (viz., regularity, duration and discussion) were added and that formed the total score of the listening behaviour parameter. Thus on the basis of total scores a respondent can be classified as low, medium and high listening behaviour categories based on class interval (exclusive) method as follows.

Respondents were interviewed through personal interview. Prior to interview, respondents were taken in to confidence by 
revealing the actual purpose of the study and full care was taken in to consideration to develop good rapport with them. For the data collection well designed and pre-tested interview scheduled were used. Collected data were analysed by the help of various statistical tools i.e. frequency, percentage and mean etc.

\section{Results and Discussion}

The data presented in Table 1 shows the distribution of respondents according to their regularity of listening agricultural information on Kisanvani programme. It is observed that majority of the respondents $(72.50 \%)$ had high regularity of listening Kisanvani programme followed by medium $(21.67 \%)$ and low $(5.83 \%)$ regularity of listening respectively.

The data presented in Table 2 shows the distribution of respondents according to their duration of listening Kisanvani programme. It is observed that majority of the respondents $(71.67 \%)$ spent more than twenty minutes duration in listening Kisanvani programme followed by medium (10-20 minutes) (25.83 $\%)$ and low (less than 10 minutes) (2.50\%) duration respectively.

The data presented in Table 3 shows the distribution of respondents according totheir discussion after listening Kisanvani programme. It is observed that majority of the respondents $(75.83 \%)$ had low discussion followed by medium (20.83\%) and high (3.34 $\%)$ discussion respectively.

The data presented in Table 4 shows the distribution of respondents according to their listening behaviour. It is observed that majority of the respondents $(54.17 \%)$ had medium listening behaviour followed by high $(35.83 \%)$ and low $(10.00 \%)$ listening behaviour respectively. Thus it may be concluded that most of the respondents had medium listening behaviour towards Kisanvani programme (Fig. 1-4).

Table.1 Distribution of respondents according to their regularity of listening agricultural information on Kisanvani programme

\begin{tabular}{|l|l|l|l|}
\hline S. No. & Categories & Frequency & Percentage $(\%)$ \\
\hline $\mathbf{1 .}$ & Low & 07 & 5.83 \\
\hline 2. & Medium & 26 & 21.67 \\
\hline $\mathbf{3 .}$ & High & 87 & 72.50 \\
\hline & Total & $\mathbf{1 2 0}$ & $\mathbf{1 0 0 . 0 0}$ \\
\hline
\end{tabular}

Table.2 Distribution of respondents according to their duration of listening Kisanvani programme

\begin{tabular}{|l|l|l|l|}
\hline S. No. & Categories & Frequency & Percentage (\%) \\
\hline $\mathbf{1 .}$ & Low (less than 10 minutes) & 03 & 2.50 \\
\hline 2. & Medium $(10-20$ minutes) & 31 & 25.83 \\
\hline 3. & High (more than 20 minutes) & 86 & 71.67 \\
\hline & Total & $\mathbf{1 2 0}$ & $\mathbf{1 0 0 . 0 0}$ \\
\hline
\end{tabular}


Table.3 Distribution of respondents according to their discussion after listening Kisanvani programme

\begin{tabular}{|l|l|l|l|}
\hline S. No. & Categories & Frequency & Percentage (\%) \\
\hline $\mathbf{1 .}$ & Low & 91 & 75.83 \\
\hline $\mathbf{2 .}$ & Medium & 25 & 20.83 \\
\hline $\mathbf{3 .}$ & High & 04 & 3.34 \\
\hline & Total & $\mathbf{1 2 0}$ & $\mathbf{1 0 0 . 0 0}$ \\
\hline
\end{tabular}

Table.4 Distribution of respondents according to their listening behavior

\begin{tabular}{|l|l|l|l|}
\hline S. No. & Categories & Frequency & Percentage (\%) \\
\hline $\mathbf{1 .}$ & Low & 12 & 10.00 \\
\hline $\mathbf{2 .}$ & Medium & 65 & 54.17 \\
\hline $\mathbf{3 .}$ & High & 43 & 35.83 \\
\hline & Total & $\mathbf{1 2 0}$ & $\mathbf{1 0 0 . 0 0}$ \\
\hline
\end{tabular}

Fig.1 Distribution of respondents according to regularity of listening

\section{Regularity of listening}

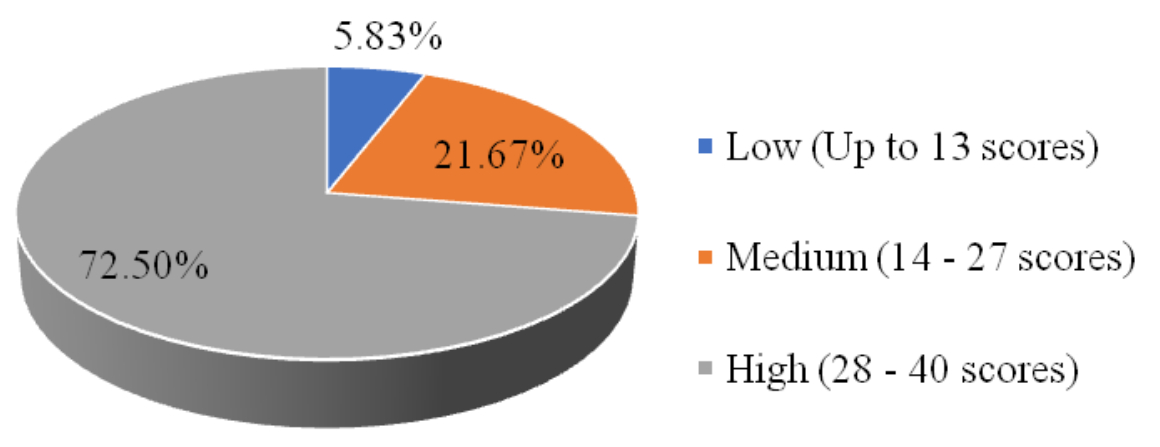

Fig.2 Distribution of respondents according to duration of listening 


\section{Duration of listening}

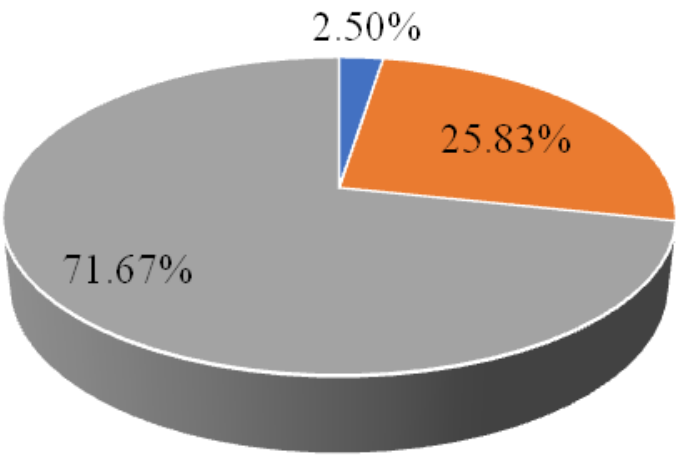

- Low (less than 10 minutes)

- Medium (10 - 20 minutes)

- High (more than 20 minutes)

Fig.3 Distribution of respondents according to discussion after listening

\section{Discussion after listening}

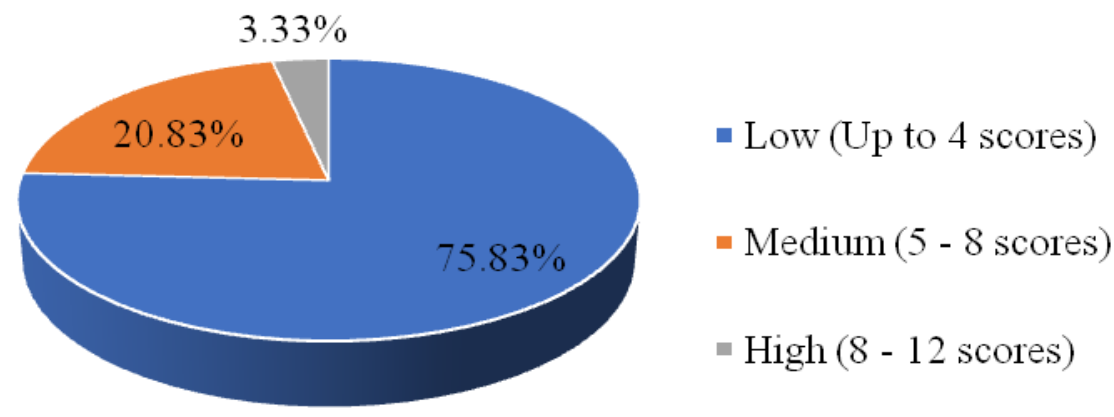

Fig.4 Distribution of respondents according to listening behaviour

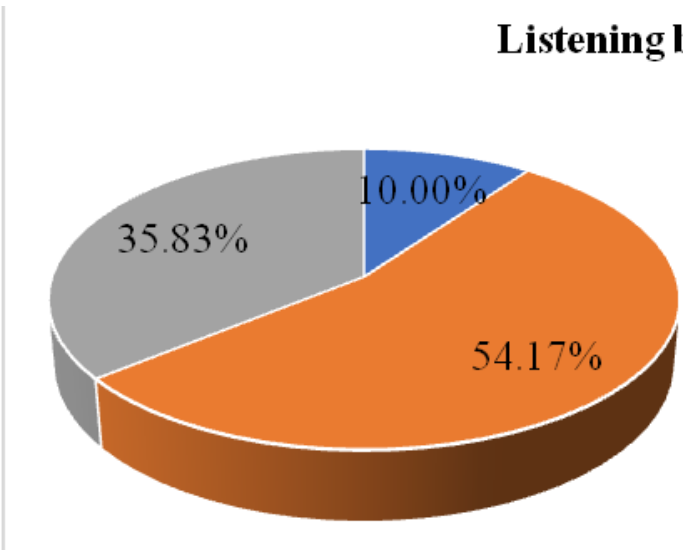

Majority of the respondents $(72.50 \%)$ had high regularity of listening Kisanvani programme. The probable reason for this may be they find agricultural information broadcasted in the programme very useful. Majority of the respondents $(71.67 \%)$ spent
- Low (Up to 18 scores)

- Medium(19 - 36 scores)

- High (37 - 55 scores) more than twenty minutes duration in listening Kisanvani programme. The probable reason for this may be they find agricultural information broadcasted in the programme very useful and interesting. Majority of the respondents $(75.83 \%)$ had low discussion 
after listening Kisanvani programme. The probable reason for this may be they do not think that it is necessary to discuss about the programme. Majority of the respondents $(54.17 \%)$ had medium listening behaviour. This may be because of farmers listen to Kisanvani programme for entertainment only. In conclusion, majority of the respondents $(72.50 \%)$ had high regularity of listening information on Kisanvani programme. Majority of the respondents $(71.67 \%)$ spend more than twenty minutes duration in listening Kisanvani programme. Majority of the respondents $(75.83 \%)$ were in low category of discussion after listening Kisanvani programme. Majority of the respondents $(54.17 \%)$ had medium listening behaviour followed by high $(35.83 \%)$ and low $(10.00 \%)$ listening behaviour respectively. Thus it can be concluded that majority of the respondents $(54.17 \%)$ had medium listening behaviour towards Kisanvani programme.

\section{Acknowledgement}

Sincere gratitude and thanks to Dr. Seema Naberia, Assistant Professor, Department of Extension Education, JNKVV, Jabalpur, Madhya Pradesh, India, for her guidance and encouragement during the achievement of M.Sc. Thesis and her help and extraordinary support in writing this manuscript.

\section{References}

Kakade O., 2013. Credibility of Radio Programmes in the Dissemination of Agricultural Information: A Case Study of Air Dharwad, Karnataka. IOSR Journal of Humanities and Social Science. 12(3): 18-22.

Khadri S.R., Goudappa S.B. and Sidramayya 2017. Radio listening behaviour and preferences of rural farmers in Raichur district of NE Karnataka. Agriculture Update. 12(TECHSEAR-7): 19901994.

Manoj Kumar., Ansari M.N. and Singh A.K. 2017.Attitude of radio listeners towards farm broadcast programmes. International Journal of Science, Environment and Technology. 6(2): 1485 - 1490 .

Mass media support to agriculture extension: Success stories of All India Radio. Web link: http://allindiaradio. gov.in/Information/Documents/394b5 26c47894d8bbe58a46a5da34a46Kisin vani_Books.pdfVisited on 22 may, 2018.

Yadav K., Kumar A., Kumar R. and Kumar R., 2017. Listening Behavior and Programme Preferences of Community Radio Listeners of CCS HAU, Hisar-91.2 MHz. International Journalof Pure and Applied Bioscience 5(3): 518-521.

\section{How to cite this article:}

Sumit Kumar Palvi*, Seema Naberia and Khare, N.K. 2018. Listening Behaviour of Audience Farmers of Shahdol District of Madhya Pradesh towards Kisanvani Programme of All India Radio. Int.J.Curr.Microbiol.App.Sci. 7(07): 3832-3837. doi: https://doi.org/10.20546/ijcmas.2018.707.445 